\title{
Controle de perdas de carotenóides em hortaliças preparadas em unidade de alimentação e nutrição hospitalar
}

\author{
Control of carotenoid loss in vegetables \\ prepared in a hospital foodservice
}

Ceres M attos Della Lucia ${ }^{1}$

Flávia M ilagres Campos²

Gardênia M árcia Silva Campos M ata ${ }^{1}$

Helena M aria Pinheiro Sant'Ana ${ }^{1}$

${ }^{1}$ Universidade Federal de Viçosa. Av. Peter Henry Rolfs, s/n, Campus Universitário. 36570-000 Viçosa MG. ceresnut@yahoo.com.br ${ }^{2} \mathrm{UNI}-\mathrm{BH}$.
Abstract The aim of this study was to assess the handling procedures of kale and tomatoes in a hospital foodservice (HFS) in order to control loss of $\beta$-caroteneand licopene. Theadopted measures, up to then not used by theH FS, were: 24-h storage under refrigeration $\left(10^{\circ} \mathrm{C}\right)$, hygienizing for $15 \mathrm{~min}$ and distribution immediately after preparation. Vegetable samples were collected after reception and after each stage of manipulation in the HFS. The samples were analyzed using high performance liquid chromatography (HPLC) with a mobile phase of methanol, ethyl acetateand acetonitrile(50:40:10). AN OVA ( $\alpha=$ 0.05 ) was used to detect significant differences. $\mathrm{N}$ o significant differences in the content of the components werefound between thedifferent stages of manipulation but there was an important decrease in the retention rates. In kale a retention rate of $68.2 \%$ for $\beta$-carotene was verified 60 minutes after preparation whereas in tomatoes $91.96 \%$ of this compound were preserved for 120 minutes after preparation. N o important decrease was observed in the retention of licopene. The high retention rates showed that the evaluated procedures contributed to control the loss of carentoids in vegetables and therefore these measures should be adopted in other HFS.

Key words Beta-carotene, Licopene, Kale, Tomato, H PLC, H ospital foodservice
Resumo Objetivou-se avaliar procedimentos de mani pulação visando o controle de perdas de $\beta$ caroteno elicopeno em couvee tomate preparados em uma U nidade de Alimentação e Nutrição (UAN) hospitalar. Oscritérios adotadosnão utilizados previamente pela UAN foram: armazenamento por $24 \mathrm{~h}$ sob refrigeração $\left(10^{\circ} \mathrm{C}\right)$, sanitização por 15 min edistribuição logo após o preparo. As hortaliças foram coletadas após a recepção e depois de cada etapa demanipulação. A análisefoi realizada por cromatografia líquida de alta eficiência (CLAE), usando como fasemóvel metanol, acetato de etila e acetonitrila (50:40:10). A AN 0 VA $(\alpha=0,05)$ foi utilizada para detecção de diferenças significativas. Não foram encontradas diferenças significativas quanto ao conteúdo dos componentesentreasetapas demanipulação, mas houve redução importantedas taxas de retenção. Para $\beta$ caroteno em couve, verificou-se retenção de $68,2 \%$ após 60 minutos de exposição para consumo, enquanto em tomate, $91,96 \%$ do conteúdo dessecomposto foi preservado após 120 minutos de espera atéa distribuição. $N$ ão foi observada redução importante na taxa de retenção de licopeno. Os procedimentos avaliados na UAN hospitalar contribuíram para controlar as perdas de carotenóides nas hortaliças, pois sua retenção foi elevada, sendo sugerida sua adoção em outras UAN .

Palavras-chave Beta-caroteno, Licopeno, Couve, Tomate, CLAE, UAN hospitalar 
Introdução

Os carotenóides são o grupo mais disseminado de pigmentos na natureza, com mais de seiscentas estruturas químicas já caracterizadas'; entre tanto, apenas cerca de cinqüenta deles possuem atividade biológica². Esses compostos vêm despertando grande interesse em virtude de sua importância na prevenção de determinados tipos de câncer (como câncer de pulmão, mama, cavidadeoral, cólon ereto), de doenças cardiovasculares e catarata, na ação inibidora nas mucosas contra úlceras gástricas e na atuação sobre o sistema imunológico.

O licopeno, um carotenóide com importante função fisiológica, é responsável pela coloração vermelho-alaranjada de frutas e hortaliças nas quais está presente. Esse carotenóide não tem atividade de provitamina $A$, mas tem um efeito protetor direto contra radicais livres, sendo considerado um potente antioxidante protetor da camada celular por reação com os radicais peróxidos ecom o oxigênio molecular, principalmente $e^{3}$. $0 \beta$-caroteno, por sua vez, além de possuir atividade provitamina $A$, apresenta propriedades antioxidantes, protegendo o corpo contra certas doenças, retardando o envelhecimento, além de ser utilizado como corante natural para produtos alimentícios².

A deficiência de vitaminaA (DVA) éconsiderada um problema grave em mais de sessenta países. Em todo o mundo, estima-se que cerca de 4,4 milhões de préescolares sofram com os sinais clínicos da carência de vitamina $A$ e que 127 milhões apresentem a deficiência na forma subclínica. M esmo os inquéritos nacionais sendo escassos, no Brasil, a prevalência de DVA está estimada entre 16 e $74 \%$ em crianças menores de seis anos ${ }^{4}$. Os inquéritos bioquímicos disponíveis no Brasil confirmam que a DVA é um problema de saúde pública nos estados de São PauIo, M inas Gerais, Pernambuco, Paraíba, Bahia e Amazonas 5 .

Dada a dificuldade de consumo dos produtos de origem animal devido ao seu custo mais elevado, as hortaliças e frutas contribuem com quantidades expressivas de provitaminas A para suprir a necessidade diária da vitamina. H ortaliças, como couve e tomate, podem ser produzidas praticamente durante todo o ano e sua aquisição é acessível para a maior parte da população. A couve (Brassica oleracea) destaca-se entre as hortaliças fol hosas ricas em carotenóides devido a sua facilidade de produção e consumo em boa parte do território nacional ${ }^{6}$.
No Brasil, o tomate (Lycopersicom esculentum) é um dos alimentos mais consumidos, seja cru ou processado, por indivíduos de todas as classes sociais. Embora não seja considerado uma fonte rica de compostos pró-vitamina A, o tomate e seus produtos merecem atenção em termos de valor de vitamina $A$ devido à facilidade de ser encontrado e de seus preços acessíveis. Por outro lado, é uma excelente fonte de licopeno. Uma vez que outros efeitos benéficos atribuídos aos carotenóides, tais como a prevenção do câncer e melhora da atividade imunológica, não são restritos aos precursores de vitamina $A$, todos os alimentos ricos em carotenóides, como o tomate, devem ser considerados 6 .

D evido à alta capacidade de oxidação dos carotenóides, o valor nutricional desses alimentos pode ser reduzido durante as diversas etapas a que são submetidos desde a colheita até a ingestão pelo consumidor? ${ }^{7}$. É de suma importância prever tais perdas e estabelecer medidas preventivas e critérios que possam ser adotados para minimizar o prejuízo nutricional tanto em domicílio, quanto em serviços de alimentação de coletividades.

Assim como os demais riscos que comprometem a qualidade dos alimentos, a perda do valor nutricional está relacionada à saúde dos consumidores e não é menos importante que as demais, embora suas conseqüências, potencialmente, só serão percebidas em médio e longo prazo. A utilização de boas práticas de manipulação no controle de perdas do valor nutricional pode ser degrandeutilidadeem Unidades deAlimentação e Nutrição (UAN). No entanto, é necessário estabelecer quais medidas podem ser tomadas para controlar a perda de vitaminas, sem ferir os critérios já estabelecidos para garantir a qualidade microbiológica ${ }^{6}$.

0 propósito desse estudo foi avaliar procedimentos de manipulação, visando à validação de critérios relativos a medidas preventivas para 0 controledeperdas de carotenóides em hortaliças preparadas em uma UAN hospitalar, por meio da avaliação do conteúdo desses nutrientes após condições padronizadas de estocagem, preparo edistribuição.

\section{M aterial e métodos}

\section{Material}

Foram utilizados couve (Brassica oleracea, var. manteiga) e tomate (Lycopersicom esculen- 
tum, var. santa cruz) coletados em uma UAN hospitalar. As amostras de couve e tomate foram transportadas até o Laboratório de Análise de Vitaminas da Universidade Federal deViçosa, embaladas em sacos plásticos, acondicionadas em isopor com gelo.

\section{Reagentes e outros materiais}

Para preparo das amostras, utilizou-se reagentes com grau de pureza para análise (p.a.). Para filtração das amostras, foram usados papel de filtro livre de cinzas Inlab, tipo 50, $9 \mathrm{~cm}$ de diâmetro; seringas descartáveis esterilizadas de $5 \mathrm{~mL}$, da Plastipack $25 \times 7$, parede fina $22 \mathrm{G} 1$; unidades filtrantes HV M illex, em polietileno, 0,45 $\mathrm{mm}$ de porosidade da M illipore, Brasil. Para preparação das fases móveis, foram utilizados metanol daTedia, USA; acetonitrila da Tedia, USA eacetato de etila O mniSolv da M allinckroat Chemicals, USA, todos grau HPLC.

Métodos

UAN colaboradora

e experimentos realizados

Participou do estudo uma UAN hospitalar demédio porte, situada na cidade de Viçosa, M G. A rotina de manipulação das hortaliças foi analisada e registrada através de formulários previamente estabelecidos.

Experimento 1: nesta fase, foi testado o efeito do armazenamento por 24 horas em temperatura de refriger ação $\left(10^{\circ} \mathrm{C}\right)$, seguido da imersão em solução sanitizante por 15 minutos, sendo realizada análise do conteúdo de carotenóides após cada uma dessas etapas. Amostras representativas de cada hortaliça foram coletadas, armazenadas em sacos plásticos, identificadas e acondicionadas em isopor com gelo para o transporte até o laboratório.

Experimento 2: nesta fase, foram analisados os efeitos das condições de sanitização por 15 minutose distribuição imediatamenteapóso pre paro. 0 tomate também foi coletado 60 e 120 minutos após o preparo e a couve refogada, 30 e 60 minutos após o preparo, para verificar se os tempos reais utilizados naUAN acarretariam perdas significativamente maiores quando comparadas aos critérios utilizados. As amostras foram coletadas após cada uma das etapas descritas ( coleta 1: após sanitização; coleta 2: logo após o preparo; demais coletas: após cada um dos tempos de espera). Como a freqüência de couve no cardápio era reduzida, somente a couve refogada teve suas concentrações de carotenóides avaliadas.

O grupo controle consistiu nas amostras de couve e tomate que não sofreram nenhum tipo de tratamento (armazenamento, sanitização ou preparo).

0 experimento foi realizado com três repetições, em diferentes dias, sempre respeitando a freqüência das hortaliças no cardápio da UAN.

Extração e análise de carotenóides

A extração e análises das amostras foram realizadas com as luzes apagadas, tomando-se 0 cuidado de proteger os pigmentos da luz e do oxigênio, usando papel alumínio para cobrir as vidrarias, frascos de vidro âmbar e cortinas do tipo black-out.

0 processo de extração ${ }^{8}$ realizado foi: pesaram-se cerca de 5 gramas de tomate e 3 gramas de couve; logo após, foram adicionados em torno de $70 \mathrm{~mL}$ de acetona resfriada à amostra, que foi triturada em microtriturador. Para as amostras de couve crua, foi utilizado um passo adicional ${ }^{9}$, que consistiu na utilização de um banho em vibrador ultrassônico, para facilitar a extração dos carotenóides, durante 20 minutos. 0 material foi filtrado a vácuo em funil de büchner utilizando-sepapel defiltro. A extração com acetona foi repetida até o resíduo do filtro setornar incolor. Em amostras de couve cuja preparação foi refogada, foi utilizado, com modificações, um procedimento ${ }^{9}$, queconsistiu na solidificação do óleo em congelador por um período de 2 horas após a trituração. Em seguida, o filtrado foi transferido, aos poucos, para um funil de separação, onde foram adicionados $50 \mathrm{~mL}$ de éter de petróleo resfriado, para que ocorresse a transferência dos pigmentos da acetona para o éter. Cada fração foi lavada com água destilada três vezes, para retirar toda a acetona.

A concentração do material foi feita da seguinte maneira: acrescentou-se sulfato de sódio anidro ao éter de petróleo para retirar qualquer resíduo de água que, porventura, tivesse restado e que pudesse prejudicar a evaporação do material; a evaporação do extrato em éter de petróleo foi feita em evaporador rotativo na temperatura de $33^{\circ} \mathrm{C}$; os pigmentos foram, então, redissolvidos em quantidadeconhecida de éter de petróleo (balão volumétrico de $25 \mathrm{~mL}$ ) e armazenados em frascos de vidro âmbar em congelador, atéa análise dos carotenóides.

O material obtido da extração de pigmentos 
foi utilizado na realização das análises por cromatografia líquida dealta eficiência (CLAE). Uma alíquota $(2 \mathrm{~mL})$ do extrato armazenado em éter de petróleo foi evaporada sob fluxo de nitrogê nio e, em seguida, recuperada em quantidade conhecida deacetona. 0 extrato foi, então, filtrado em unidade filtrante HV M illex e injetado na coluna cromatográfica para análise. As condições cromatográficas $^{10}$, com algumas modificações foram: cromatógrafo líquido de alta eficiência, Shimadzu, munido de bomba de alta pressão, modelo LC-10AT VP; injetor automático com loop de 50 $\mu \mathrm{L}$, modelo SIL-10AF; detector de arranjo de diodos UV-Visível, modelo SPDM 10A; software M ulti System modelo Class VP 6.12, para controledeaté 4 sistemas; coluna Phe nomenex C18, 250 x 4,6 mm; $5 \mu \mathrm{m}$; fase móvel composta de metanol: acetato de etila: acetonitrila (50:40:10); fluxo: $1,5 \mathrm{~mL} /$ minuto; tempo de corrida de 9 minutos. Os cromatogramas foram lidos a $450 \mathrm{~nm}$. As análises e pós-análises foram controladas por um computador acoplado ao sistema.

Preparo das curvas padrão, identificação e quantificação de carotenóides

Para construção da curva padrão de $\beta$-caroteno, após a quantificação em espectrofotômetro, foram injetados 5 e $10 \mu \mathrm{L}$ de uma solução de $5 \mu \mathrm{g} / \mathrm{mL} ; 20$, 30 e $50 \mu \mathrm{L}$ de uma solução de 10 $\mu \mathrm{g} /$ $\mathrm{mL} ; 50 \mu \mathrm{L}$ de uma solução de $20 \mu \mathrm{g} / \mathrm{mL}$ e $50 \mu \mathrm{L}$ de uma solução de $40 \mu \mathrm{g} / \mathrm{mL}$ de $\beta$-caroteno (Sigma, USA). Para a curva padrão de licopeno, utilizouse como padrão o pigmento extraído de tomate, separado por cromatografia de coluna aberta e quantificado por espectrofotometria. Foram injetados 15, 30 e 50 $\mu \mathrm{L}$ de uma solução 7,88 mg/ $\mathrm{mL}$ e 30 e $50 \mathrm{~mL}$ de uma solução $1,97 \mu \mathrm{g} / \mathrm{mL}$ de licopeno.

A identificação dos componentes nas amostras dehortaliças foi feita comparando-seos tempos de retenção obtidos para os padrões e para as amostras, analisados sob as mesmas condições. Além disso, foram comparados os espectros de absorção dos padrões e dos picos de interesse nas amostras, utilizando o detector de arranjos de diodos.

A partir das curvas padrão obtidas, foi cal culada a concentração dos compostos presentes nas amostras. 0 valor real da concentração nas amostras foi obtido pelos cálculos das diluições realizadas.

\section{Cálculos}

As porcentagens de retenção de $\beta$-caroteno e licopeno foram calculadas deacordo com a equação: 100 - [(conteúdo inicial - conteúdo final) / conteúdo inicial x 100], em que o conteúdo inicial corresponde à amostra controle (antes de qualquer manipulação) e o conteúdo final às amostras após todas as etapas de manipulação.

Para que pudessem ser realizadas comparações entre as quantidades reais de $\beta$-caroteno e licopeno na couve crua e refogada, as porcentagens de retenção real dos compostos foram calculadas de acordo com seguinte equação":

$$
\begin{gathered}
\% R R=\frac{\begin{array}{c}
\text { conteúdo do composto por grama de } \\
\text { alimento cozido } \times \text { peso em grama do } \\
\text { alimento cozido } \times 100
\end{array}}{\begin{array}{c}
\text { conteúdo do composto por grama de } \\
\text { alimento cru } \times \text { peso em grama do } \\
\text { alimento cru }
\end{array}} \\
\text { Onde RR }=\text { retenção real }
\end{gathered}
$$

\section{Resultadosediscussão}

Procedimentos operacionais utilizados pela UAN

A partir das observações do processo de produção das hortaliças estudadas, evidenciou-se a presença de condições que provavel mente estariam contribuindo para a perda de carotenóides, como: transporte inadequado das hortaliças até a UAN; falhas durante o processo de sanitização (as hortaliças não ficavam completamente submersas na solução); manutenção das hortaliças em temperatura ambiente após o preparo; e o grande intervalo de tempo entre o preparo e a distribuição (Quadro 1).

\section{Análises qualitativas}

O perfil cromatográfico obtido para $\beta$-caroteno elicopeno mostra uma eficiente separação, indicando que a quantificação dos teores nas amostras foi realizada de forma confiável (Figura 1).

\section{Análises quantitativas}

O conteúdo de $\beta$-caroteno e licopeno nas amostras relativas ao armazenamento eà sanitização (experimento 1) não apresentou diferença estatisticamente significativa em relação ao con- 
Quadro 1. Condições de transporte, recepção, armazenamento, preparo e distribuição de hortaliças na UAN hospitalar.

\begin{tabular}{|c|c|c|}
\hline \multirow[b]{2}{*}{ Etapas } & \multicolumn{2}{|c|}{ Hortaliça } \\
\hline & Couve & Tomate \\
\hline Transporte & $\begin{array}{l}\text { A UAN conta com dois fornecedores. Um } \\
\text { deles (produtor rural) realiza o transporte } \\
\text { em caminhonete aberta, o outro (fornece- } \\
\text { dor local) em motocicleta. Em ambos, a } \\
\text { hortaliça é acondicionada em sacos plásti- } \\
\text { cos e em caixas de polietileno coloridas, } \\
\text { mas só o produtor rural as cobre com lona } \\
\text { plástica. Geral mente colhida cerca } 14 \text { h } \\
\text { antes da entrega (produtor rural). }\end{array}$ & $\begin{array}{l}\text { A UAN conta com um fornecedor local. } 0 \\
\text { transporte é realizado em motocicleta, sen- } \\
\text { do quea hortaliça é acondicionada em sacos } \\
\text { plásticos e em caixas de polietileno. }\end{array}$ \\
\hline Recepção & $\begin{array}{l}\text { Quando servida no jantar, a recepção ocorre } \\
\text { no mesmo dia do preparo. Quando servida } \\
\text { no almoço, a recepção geralmente ocorre } \\
\text { no dia anterior. }\end{array}$ & $\begin{array}{l}\text { Quando maduro e servido no jantar, a re- } \\
\text { cepção ocorre no mesmo dia do preparo. } \\
\text { Quando servido no almoço, a recepção ocor- } \\
\text { re no dia anterior. }\end{array}$ \\
\hline Armazenamento & $\begin{array}{l}\text { Acondicionamento em geladeira (em } \\
\text { torno de } 10^{\circ} \mathrm{C} \text { ) em sacosplásticos da própria } \\
\text { instituição até o momento do pré-preparo. }\end{array}$ & $\begin{array}{l}\text { Tomates verdes: armazenamento em sacos } \\
\text { plásticos do fornecedor na área de estoca- } \\
\text { gem seca até maturação. Tomates maduros: } \\
\text { Acondicionamento em geladeira (em tor- } \\
\text { no de } 10^{\circ} \mathrm{C} \text { ) em sacos plásticos próprios da } \\
\text { instituição até o momento do pré-preparo. }\end{array}$ \\
\hline $\begin{array}{l}\text { Higienização e } \\
\text { pré-preparo }\end{array}$ & $\begin{array}{l}\text { As folhas são lavadas individualmente em } \\
\text { água corrente. As partesinaproveitáveis são } \\
\text { retiradas manualmente. A sanitização } \\
\text { ocorre em solução de hipoclorito de sódio } \\
\text { (marca desconhecida), durantecerca de } 15- \\
20 \text { minutos. Para cada } 1 \mathrm{~L} \text { de água, são } \\
\text { colocados 50mL de hipoclorito. }\end{array}$ & $\begin{array}{l}\text { Os tomates, quando maduros, são lavados } \\
\text { individualmente em água corrente. A sani- } \\
\text { tização corre em solução de hipoclorito de } \\
\text { sódio (marca desconhecida), durante cerca } \\
\text { de } 15-25 \text { minutos. Para cada } 1 \mathrm{~L} \text { de água, são } \\
\text { colocados } 50 \mathrm{~mL} \text { de hipoclorito. }\end{array}$ \\
\hline Preparo & $\begin{array}{l}\text { Fatiada com faca, no setor de pré-preparo } \\
\text { de vegetais. Armazenada novamente em } \\
\text { geladeira (em torno de } 10^{\circ} \mathrm{C} \text { ) por } \\
\text { aproximadamente } 2 \text { horas até o início da } \\
\text { distribuição. }\end{array}$ & $\begin{array}{l}\text { São cortados em quatro quadrantes, tendo } \\
\text { as partes inaproveitáveis retiradas. São, pos- } \\
\text { teriormente, cortados em cubinhos, com um } \\
\text { picador manual de vegetais. Também são } \\
\text { servidos fatiados em rodelas, com o auxílio } \\
\text { de uma faca. Armazenados novamente em } \\
\text { geladeira (em torno de } 10^{\circ} \mathrm{C} \text { ) por cerca de } 2 \\
\text { horas até o início da distribuição. }\end{array}$ \\
\hline Distribuição & $\begin{array}{l}\text { Quando refogada, a diferença entre o } \\
\text { primeiro tempo de espera e o último } \\
\text { (quando o último paciente recebe a } \\
\text { refeição) é de aproximadamente } 1 \text { hora. }\end{array}$ & $\begin{array}{l}\text { A diferença entre o primeiro tempo de es- } \\
\text { pera (quando o tomate retorna à geladeira, } \\
\text { após ser preparado) e o último (quando o } \\
\text { último paciente recebe a refeição) é de apro- } \\
\text { ximadamente } 2 \text { horas. }\end{array}$ \\
\hline
\end{tabular}

trole, em ambas as hortaliças estudadas (Tabela 1). Os valores de retenção foram elevados, o que demonstra que os critérios sugeridos para estocagem e sanitização parecem ter minimizado as perdas de $\beta$-caroteno e licopeno que poderiam estar ocorrendo com as condições operacionais utilizadas como rotina. Os teores de licopeno variaram entre 1074,26 e $1576,14 \mu \mathrm{g} / 100 \mathrm{~g}$ eos de $\beta$-caroteno entre 625,82 e $661,33 \mu \mathrm{g} / 100 \mathrm{~g}$ em tomate. A variação do conteúdo de carotenóides em tomates estáintimamenterelacionadaà variedade e ao grau de maturação, já que são esses os principais pigmentos responsáveis pela alteração de cor durante 0 amadurecimento ${ }^{11}$. Ao testar a 

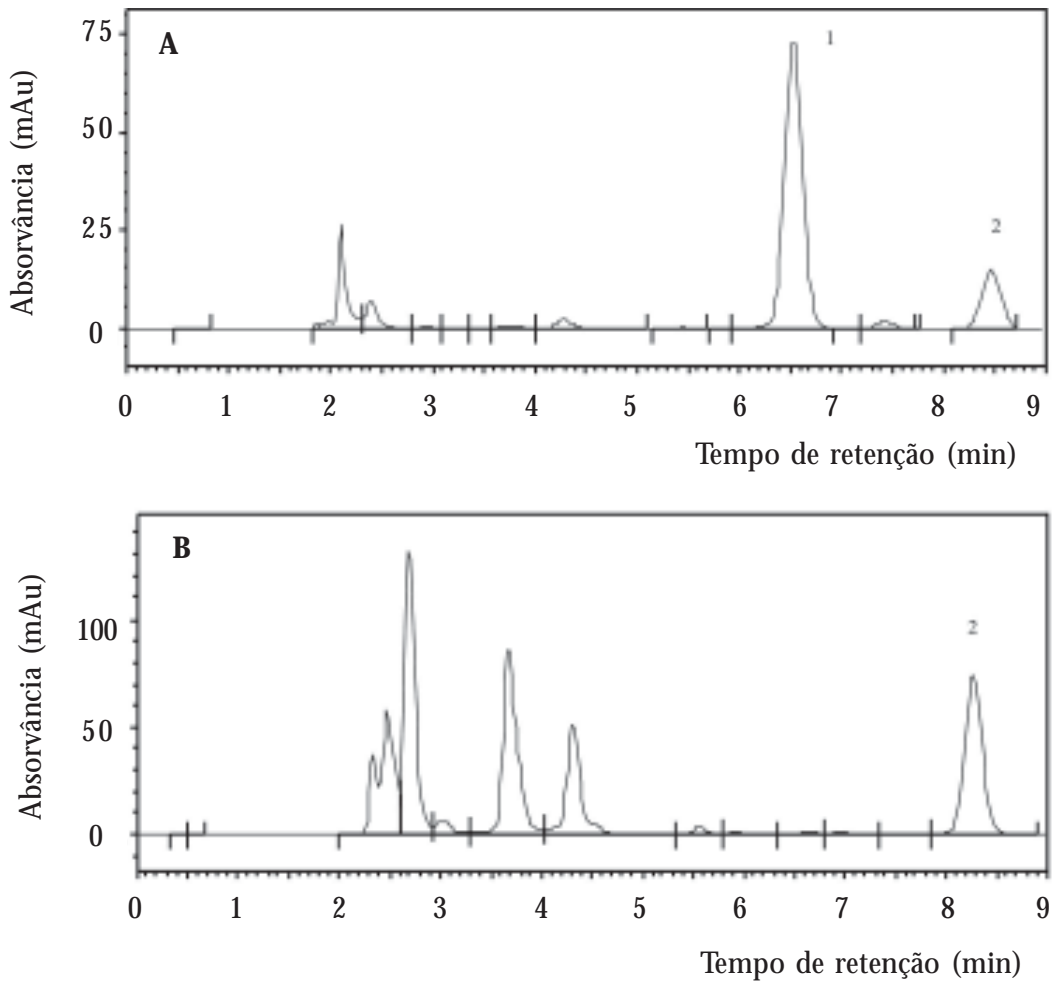

Figura 1. Análise por CLAE de licopeno (1) e $\beta$-caroteno (2) em tomate (A) e couve (B). Condições cromatográficas: Fase móvel: metanol, acetato de etila, acetonitrila (50:40:10); Coluna Phenomenex C18, $5 \mu \mathrm{m}, 250$ x 4,6 mm; detector de arranjos de diodos; vazão: 1,5 mL/min; volume de injeção: $30 \mu \mathrm{L}$ (tomate) e $10 \mu \mathrm{L}$ (couve).

Tabela 1. Conteúdo e retenção de carotenóides e valor de vitamina A nas hortaliças (experimento 1).

\begin{tabular}{|c|c|c|c|c|c|c|}
\hline & \multicolumn{2}{|c|}{ Controle** } & \multicolumn{2}{|c|}{ Armazenamento } & \multicolumn{2}{|c|}{ Sanitização } \\
\hline & Couve* & Tomate* & Couve* & Tomate* & Couve* & Tomate* \\
\hline$\beta$-caroteno $(\mu \mathrm{g} / 100 \mathrm{~g})$ & $\begin{array}{r}5838,32 \\
+801,29 a\end{array}$ & $\begin{array}{r}661,33 \\
\pm 55,14 b\end{array}$ & $\begin{array}{r}5436,16 \\
\pm 612,02 \mathrm{a}\end{array}$ & $\begin{array}{r}625,82 \\
\pm 10,38 b\end{array}$ & $\begin{array}{c}5124,94 \\
\pm 650,49 a\end{array}$ & $\begin{array}{r}630,03 \\
+65,21 b\end{array}$ \\
\hline Retenção de $\beta$-caroteno (\%) & - & - & $\begin{array}{r}93,57 \\
\pm 9,23\end{array}$ & $\begin{array}{r}95,02 \\
\pm 6,99\end{array}$ & $\begin{array}{r}94,66 \\
\pm 11,95\end{array}$ & $\begin{array}{r}100,75 \\
\pm 11,24\end{array}$ \\
\hline $\begin{array}{l}\text { Valor de vitamina } A \\
(\mu \mathrm{g} \text { de retinol } / 100 \mathrm{~g})\end{array}$ & $\begin{array}{r}486,53 \\
+66,77\end{array}$ & $\begin{array}{r}55,11 \\
\pm 4,59\end{array}$ & $\begin{array}{r}453,01 \\
\pm 51,00\end{array}$ & $\begin{array}{r}52,15 \\
\pm 0,86\end{array}$ & $\begin{array}{r}427,08 \\
\pm 54,21\end{array}$ & $\begin{array}{r}52,50 \\
\pm 5,43\end{array}$ \\
\hline Licopeno ( $\mu \mathrm{g} / 100 \mathrm{~g})$ & - & $\begin{array}{r}1182,21 \\
\pm 646,37 b\end{array}$ & - & $\begin{array}{r}1576,14 \\
\pm 687,53 b\end{array}$ & - & $\begin{array}{r}1074,26 \\
\pm 718,87 \mathrm{~b}\end{array}$ \\
\hline Retenção de licopeno (\%) & - & - & - & $\begin{array}{r}138,68 \\
\pm 14,76\end{array}$ & - & $\begin{array}{r}68,59 \\
\pm 9,14\end{array}$ \\
\hline
\end{tabular}

Os valores correspondem à média + desvio-padrão (DP) de três repetições.

* M édias seguidas pela mesma letra nas linhas não diferem entre si $(P>0,05)$ pela análise de variância.

${ }^{*}$ Controle: não sofreu armazenamento esanitização.

Retenção $=100$ - [(teor do componentena amostra controle- teor do componentena amostra apóstratamento) / (teor do componente na amostra controlex 100)]. 
influência da temperatura de armazenamento e o tempo de sanitização nos teores de licopeno e $\beta$-caroteno em tomates, não foram verificadas diferenças estatisticamentesi gnificativas no conteúdo quanto ao tipo de estocagem (em temperatura ambiente ou sob refrigeração) nem quanto ao tempo de sanitização $0^{6}$. No presente trabaIho, 0 armazenamento por 24 horas sob refrigeração e a imersão em solução sanitizante tam- bém não influenciaram significativamenteos teores e as retenções de licopeno e $\beta$-caroteno dos tomates. Em couve, o conteúdo de $\beta$-caroteno variou entre 5124,94 e5838,32 $\mu \mathrm{g} / 100 \mathrm{~g}$, sem diferenças significativas quanto ao armazenamento e à sanitização.

A Tabela 2 mostra os resultados obtidos para 0 experimento 2. Primeiramente, analisou-se 0 efeito do armazenamento seguido de sanitização

Tabela 2. Conteúdo e retenção de $\beta$-caroteno, licopeno e valor de vitamina A nas hortaliças (experimento 2).

\begin{tabular}{|c|c|c|c|c|}
\hline & \multicolumn{2}{|c|}{ Controle $e^{* *}$} & \multicolumn{2}{|c|}{ Armazenamento/Sanitização } \\
\hline & Couve* $^{*}$ & Tomate* & Couve* $^{*}$ & Tomate $^{*}$ \\
\hline $\begin{array}{l}\beta \text {-caroteno } \\
(\mu \mathrm{g} / 100 \mathrm{~g})\end{array}$ & $\begin{array}{r}7409,20 \\
+1918,49 a\end{array}$ & $\begin{array}{r}759,54 \\
\pm 120,7 \mathrm{~b}\end{array}$ & $\begin{array}{c}6249,03 \\
\pm 1520,45 a\end{array}$ & $\begin{aligned} & 756,4 \\
+ & 143,66 \mathrm{~b}\end{aligned}$ \\
\hline Retenção (\%) & - & - & $\begin{array}{r}85,25 \\
+10,95\end{array}$ & $\begin{array}{r}100,02 \\
\pm 13,80\end{array}$ \\
\hline $\begin{array}{l}\text { Valor de vitamina } A \\
(\mu \mathrm{g} \text { de retinol/100g) }\end{array}$ & $\begin{array}{r}617,43 \\
+159,87\end{array}$ & $\begin{array}{c}63,29 \\
\pm 10,06 \mathrm{~b}\end{array}$ & $\begin{array}{c}520,75 \\
+126,70\end{array}$ & $\begin{array}{c}63,03 \\
\pm 11,97 \mathrm{~b}\end{array}$ \\
\hline $\begin{array}{l}\text { Licopeno } \\
(\mu \mathrm{g} / 100 \mathrm{~g})\end{array}$ & - & $\begin{array}{r}619,56 \\
\pm 84,06 \mathrm{~b}\end{array}$ & - & $\begin{aligned} & 600,11 \\
+ & 1903,99 b\end{aligned}$ \\
\hline Retenção (\%) & - & - & - & $\begin{array}{r}95,23 \\
+19,45\end{array}$ \\
\hline
\end{tabular}

\begin{tabular}{|c|c|c|c|c|c|c|}
\hline & \multicolumn{2}{|c|}{ Tempo $0^{* * *}$} & \multicolumn{2}{|c|}{ Tempo $1^{* * *}$} & \multicolumn{2}{|c|}{ Tempo $2^{* * *}$} \\
\hline & Couve $^{*}$ & Tomate ${ }^{*}$ & Couve* $^{*}$ & Tomate* & Couve* & Tomate* \\
\hline $\begin{array}{l}\beta \text {-caroteno } \\
(\mu \mathrm{g} / 100 \mathrm{~g})\end{array}$ & $\begin{array}{c}4856,22 \\
\pm 1507,52 a\end{array}$ & $\begin{array}{c}631,24 \\
\pm 200,15 b\end{array}$ & $\begin{array}{c}6468,91 \\
+2445,92 a\end{array}$ & $\begin{array}{r}635,97 \\
\pm 70,74 \mathrm{~b}\end{array}$ & $\begin{array}{c}6050,61 \\
+1626,22 a\end{array}$ & $\begin{array}{c}697,52 \\
+158,99 \mathrm{~b}\end{array}$ \\
\hline Retenção (\%) & $\begin{array}{r}53,74 \\
\pm 4,37\end{array}$ & $\begin{array}{r}83,59 \\
+24,88\end{array}$ & $\begin{array}{r}70,91 \\
\pm 9,97\end{array}$ & $\begin{array}{r}84,90 \\
+7,20\end{array}$ & $\begin{array}{r}68,20 \\
\pm 13,20\end{array}$ & $\begin{array}{r}91,96 \\
\pm 8,62\end{array}$ \\
\hline $\begin{array}{l}\text { Valor de vitamina } A \\
(\mu \mathrm{g} \text { de retinol/100g) }\end{array}$ & $\begin{array}{c}406,68 \\
\pm 125,63\end{array}$ & $\begin{array}{c}52,60 \\
\pm 16,68 \mathrm{~b}\end{array}$ & $\begin{aligned} & 539,07 \\
+ & 203,83\end{aligned}$ & $\begin{array}{r}53,00 \\
\pm 5,89 \mathrm{~b}\end{array}$ & $\begin{array}{c}504,22 \\
+135,52\end{array}$ & $\begin{array}{c}58,13 \\
\pm 13,25 b\end{array}$ \\
\hline $\begin{array}{l}\text { Licopeno } \\
(\mu \mathrm{g} / 100 \mathrm{~g})\end{array}$ & - & $\begin{array}{c}1297,31 \\
\pm 761,68 \mathrm{~b}\end{array}$ & - & $\begin{array}{r}1122,58 \\
\pm 468,50 \mathrm{~b}\end{array}$ & - & $\begin{array}{c}761,95 \\
\pm 332,23 \mathrm{~b}\end{array}$ \\
\hline Retenção (\%) & - & $\begin{array}{r}204,19 \\
\pm 9,34\end{array}$ & - & $\begin{array}{l}199,98 \\
\pm 7,00\end{array}$ & - & $\begin{array}{r}127,21 \\
\pm 30,48\end{array}$ \\
\hline
\end{tabular}

O s valores correspondem à média + desvio-padrão de três repetições.

* M édias seguidas pela mesma letra nas linhas não diferem entre si $(P>0,05)$ pela análise de variância.

${ }^{*}$ Controle: não sofreu armazenamento, sanitização, fatiamento ou cocção.

*** Tempo 0: logo após o preparo; tempo 1: 30 ou 60 minutos após o preparo (couve etomate, respectivamente); tempo 2: 60 ou 120 minutos após o preparo (couveetomate, respectivamente).

Retenção $=100$ - [(teor do componenteno controle-teor do componenteapós tratamento) / (teor do componenteno controlex 100)]. 
sobre a amostra controle, que não sofreu tratamentos. Os tempos de espera até a distribuição $(0,60$ e 120 minutos para o tomate e 0,30 e 60 minutos para a couve) foram comparados à amostra obtida após armazenamento e sanitização. Os teores de licopeno variaram entre 600,11 e $1297,31 \mu \mathrm{g} / 100 \mathrm{~g}$ e os de $\beta$-caroteno entre 631,24 e $759,54 \mu \mathrm{g} / 100 \mathrm{~g}$ em tomate. Em couve, os conteúdos de $\beta$-caroteno variaram entre 4856,22 e $7409,20 \mu \mathrm{g} / 100 \mathrm{~g}$.

Em um estudo ${ }^{6}$, observou-se que o tipo de corte e o tempo de exposição para consumo não interferiram no conteúdo de $\beta$-caroteno em tomates, não sendo possível determinar quais práticas de manipulação seriam mais indicadas para o fatiamento e a distribuição para consumo. A pesar disso, sabe-se que o aumento do tempo e da superfície de exposição ao oxigênio e a luz podem elevar as perdas denutrientes em alimentos. Desta forma, recomenda-se principalmente reduzir o tempo entre o preparo e o consumo.

Observa-se que não houve diferença estatisticamente significativa entre os conteúdos de $\beta$ caroteno e licopeno nas hortaliças estudadas durante as diferentes etapas de manipulação, quando comparadas ao controle (Tabela 2). Ressalta-se que, mesmo durante o processo de cocção da couve, as perdas, em termos de conteúdo, não foram observadas. Entretanto, quando se analisa a retenção de $\beta$-caroteno em couve, verifica-se que apenas $68,2 \%$ de seu conteúdo inicial foi preservado após 60 minutos de exposição. Em tomate, ao contrário, as perdas foram bastante reduzidas: após 120 minutos de espera até a distribuição, 91,96\% do conteúdo inicial de $\beta$ caroteno foi preservado, possivelmente devido ao fato de a casca do tomate ter exercido efeito protetor, evitando possíveis perdas para o meio.

N esse estudo, para as amostras de couve cuja preparação foi refogada, utilizou-se como procedimento a solidificação do óleo e sua retirada, visando à substituição da saponificação e reduzindo as chances de perdas durante a extração ${ }^{9}$. Alguns estudos ${ }^{10,13,14}$ têm realizado a saponificação em certos tipos de amostras para hidrolisar ésteres de carotenóides e remover interferentes, como clorofilas. Na maioria dos casos, a saponificação resulta em perda de carotenóides ${ }^{12}$. Para amostras com alta concentração de lipídios, a saponificação pode exigir condições mais drásticas, o que pode causar perda dos carotenóides em estudo ${ }^{13}$.

Vários autores têm descrito perdas de carotenóides, quando as amostras são submetidas a diferentes processos culinários ${ }^{12}$. Sabe-se que 0 tempo e a temperatura de cocção podem causar degradação dos carotenóides ${ }^{10}$.

Entretanto, ainda há divergência na literatura sobre os efeitos do cozimento sobre o teor de carotenóides de vegetais. Alguns autores mostram que o cozimento pode causar perda ${ }^{15}$, enquanto outros estudos encontraram resultados opostos, em que as perdas foram inexistentes ou houveaumento dosteores ${ }^{12-14}$. Esteaumento tem sido atribuído a uma maior eficiência na extração devido ao fato do tratamento térmico inativar enzimas oxidativas e desnaturar os complexos carotenóide-proteína existente nas células vegetais ${ }^{14}$.

Alguns estudos têm mostrado que a biodisponibilidade de carotenóides em vegetais pode aumentar com o processamento ${ }^{16}$. Em revisão sobre o efeito do processamento de vegetais sobre a biodisponibilidade de carotenóides ${ }^{17}$, concluiu-se que o tratamento térmico pode aumentar a biodisponibilidade. Assim, é possível que, mesmo havendo perdas significativas após o processamento, os carotenóides que se mantêm sejam melhor absorvidos. 0 licopeno, por exemplo, tem sua biodisponibilidade aumentada com o processamento, devido à liberação da matriz do alimento. Com isso, molho de tomate e purê de tomate são tidos como melhores fontes biodisponíveis de licopeno do que as demais fontes de alimentos não cozidos, tais como o tomate $\mathrm{cru}^{4}$.

U tilizando o fator de conversão para $\beta$-caroteno, em que $12 \mu \mathrm{g}$ de $\beta$-caroteno equivalem a 1 Equivalente de Atividade de Retinol (RAE) ${ }^{18}$, pode-se calcular o valor de vitamina A das hortaliças estudadas. U ma porção de $100 \mathrm{~g}$ de tomate analisado nesta pesquisa fornece 56 ìg de retinol, equivalentes a $9 \%$ e $11 \%$ das necessidades diárias para homens e mulheres adultos, respectivamente. Já uma porção de $100 \mathrm{~g}$ de couve fornece, em média, $494 \mu \mathrm{g}$ de retinol, correspondentes a $80 \%$ das necessidades diárias de homens e 92\% das necessidades diárias de mulheres ${ }^{18}$.

\section{Conclusão}

Para a manipulação de couve e tomate em UAN, recomenda-se 0 armazenamento em temperatura de refrigeração, imersão em solução sanitizante pelo tempo recomendado pelo fabricante (15 minutos) e distribuição imediatamente após o preparo.

Os critérios avaliados naUAN hospitalar contribuem para controlar as perdas de carotenói- 
des nas hortaliças, uma vez que, de maneira geral, a retenção dos componentes foi elevada. Sugere-se a adoção dos critérios utilizados em outras UAN .

\section{Colaboradores}

CM Della Lucia trabalhou na pesquisa e na metodologia; FM Campos, na concepção do projeto e nas análises estatísticas; GM SC M ata, na metodologia e H M Pinheiro-Sant'Ana, na concepção do projeto, na orientação e na revisão final do artigo.

\section{Agradecimentos}

Ao PIBIC/CN Pq/UFV, pelo apoio financeiro.

\section{Referências}

1. Fraser PD, Bramley PM. The biosynthesis and nutritional uses of carotenoids. Progress in Lipid Research 2004; 43:228-265.

2. Olson JA. Carotenoids. In: Shils ME, OIson JA, Shike $M$, Ross AC. M odern nutrition in health and disease. Baltimore: Williams \& Wilkins; 1999. p.525-541.

3. Moritz B, Tramonte VLC. Biodisponibilidade do licopeno. Rev Nutr [periódico da Internet]. 2006. [acessado 2006 Ago 11]; 19(2): [cerca de 6 páginas]. Disponível em: http://www.scielo.br/scielo.php? script=sci_arttext $\&$ pid $=$ S1415-52732006000200013 $\&$ Ing $=$ en $\&$ nrm $=$ iso $>$

4. West Jr KP. Extent of vitamin A deficiency among preschool children and women of reproductive age. J Nutr 2002; 132:2857-2866.

5. Ramalho RA, Flores H, Saunders C. Hipovitaminose A no Brasil: um problema de saúde pública. Rev. Saúde Pública 2002; 34:56-63.

6. Campos FM. Avaliação de práticas de manipulação de hortaliças visando a preservação de vitamina $C$ e carotenóides [dissertação]. Viçosa (M G): Universidade Federal de Viçosa; 2006.

7. Bianchi M LP, Antunes LMG. Radicais livres e os principais antioxidantes da dieta. Rev Nutr 1999; 12(2):123-130.

8. Rodriguez DB, Raymundo LC, Lee T, Simpson KL, Chichester $\mathrm{CO}$. Carotenoid pigment changes in ripening M omordica charantia fruits. Ann Botanic 1976; 40:615-624.

9. De Sá MC, Rodriguez-Amaya D. Optimization of HPLC quantification of carotenoids in cooked green vegetables - Comparison of analytical and calculated data. J Food Composition Anal 2004; 17:37-51.

10. Pinheiro-Sant'ana H M , Stringheta PC, Brandão SCC, Azeredo RMC. Carotenoid retention and vitamin A value in carrot (Daucus carota L.) prepared by food service. Food Chem 1998, 61:145-51.

11. Lois LM, Rodríguez-Concepción M, Gallego F, Campos N, Boronat A. Carotenoid biosynthesis during tomato fruit development: regulatory role of 1-deoxy-D-xylulose 5-phosphate synthase. The Plant J 2000; 22(6):503-513.

12. Granado F, Olmedilla B, Blanco I, Rojas-Hidalgo E. Carotenoid composition in raw and cooked Spanish vegetables. J Agric Food Chem 1992; 40:2135-2140.

13. Hart DJ, Scott KJ. Development and evaluation of an HPLC method for the analysis of carotenoids in foods, and the measurement of the carotenoid content of vegetables and fruits commonly consumed in the UK. Food Chem 1995; 54:101-111. 
14. Lessin WJ, Catigani GL, Schwartz SJ. Quantification of cis-trans isomers of provitamin a carotenoids in fresh and processed fruits and vegetables. J Agric Food Chem 1997; 45:3728-3732.

15. Godoy HT, Rodriguez-Amaya DB. Occurrence of cis-isomers of provitamins A in Brazilian vegetables. J Agric Food Chem 1998; 46:3081-3086.

16. Rock CL. Carotenoids: biology and treatment. Pharm Ther 1997; 6(3):185-197.

17. H of KHVH, Gartner C, West CE, Tijburg LBM . Potential of vegetable processing to increase the delivery of carotenoids to man. Int J Vitamin Nutr Res 1998; 68(6):366-370

18. Institute of Medicine. Food and Nutrition Board. Standing Committee on the Scientific Evaluation of Dietary Reference Intakes. Dietary Reference Intakes: for Vitamin A, Vitamin K, Arsenic, Boron, Cromium, Copper, Iodine, Iron, M anganese, M olybdenium, Nickel, Silicon, Vanadium and Zinc. Washington: National Academy Press; 2001.

Artigo apresentado em 12/01/2006

Aprovado em 20/07/2007

Versão final apresentada em 28/06/2007 